\title{
Medical library and information services
}

\author{
R. B. TABOR \\ A.L.A. \\ Regional Librarian, Wessex Regional Hospital Board, Southampton
}

\begin{abstract}
Summary
The medical libraries in the Postgraduate Medical Education Centres which are now being built in many regions are generally of a simple pattern based on traditional library practices.

In view of the recent advances in information science it is suggested that a more radical approach should be made to the design of medical library and information centres.

The basic requirements for medical information in relation to education and medical practice are discussed together with recommendations for a regional and national network for the co-ordination of information-handling in the field of the health sciences.
\end{abstract}

\section{A new era for medical information}

Continuing medical education in the local hospital situation is a matter of considerable and increasing concern, and postgraduate centres are being planned and built in most regions. A prominent feature of these centres is the medical library but there is some doubt whether such libraries are being planned with sufficient regard to modern developments in information handling. It has been suggested that the latter half of the Twentieth Century may well become known as the age of information. More knowledge is being generated at the present time, and at a faster rate, than at any previous time in the history of mankind. Science and technology are progressing so rapidly, and over so wide a field, that it is increasingly difficult to keep pace with developments. This has led to the corresponding exponential rate of increase in the published literature, and yet this is only a part of the great mass of facts and data currently being produced.

The fact of the 'information explosion' and its importance to the biomedical sciences has begun to be studied, especially in the United States. Vern Pings (1966) has pointed out the urgency and scope of this problem and has insisted that a new and radical approach is needed to the organization of libraries in hospitals. This has again been echoed by Scott Adams (1968) of the National Library of Medicine, Washington, who says that: 'libraries in hospitals are not only understaffed and inadequately prepared for their task, but they are con- ceptually out of phase with what the future may demand of them'. In 1964 the Lancet described British hospital libraries as 'hopelessly inadequate' and 'too bizarre and too old to contain reliable or relevant information'. But in the present development of medical libraries in postgraduate centres the totality of the problem of medical information appears to be overlooked. The result is that a large number of book collections are being assembled based on ideas and techniques which are no longer entirely relevant to the contemporary situation.

Overhage (Overhage \& Harman, 1965) has pointed to three kinds of crisis facing university libraries, which apply equally to medical libraries; the physical crisis produced by the sheer bulk of the material; the operational crisis arising from the time required to process each item and the resulting cost; and the intellectual crisis deriving from the enormously complicated structure of the total knowledge of the present day which makes the retrieval of a particular piece of information a slow and costly affair. This library problem would appear to be a particular manifestation of a more general overloading of the channels of communication among scholars. Medicine itself is advancing so rapidly over so wide a front that the present trends are towards greater specialization-in number and in depth-and communication between specialties is becoming increasingly difficult. It would thus seem opportune to examine the problem of information in the health sciences, delineating the objectives of library and information services so that the future may be planned in line with developments in the rest of the scientific and technological world.

\section{Primary requirements for medical information}

Information may be defined as communicated knowledge, and it is the function of a library or information centre to mediate knowledge though such mediation need not necessarily be in the form of the printed word. Indeed, the horizons of the medical library require considerable widening. Medical libraries must be willing to accept an educational role that is much wider than that of today and there is a need for them to adopt a new philosophy in the area of service. This must include, 


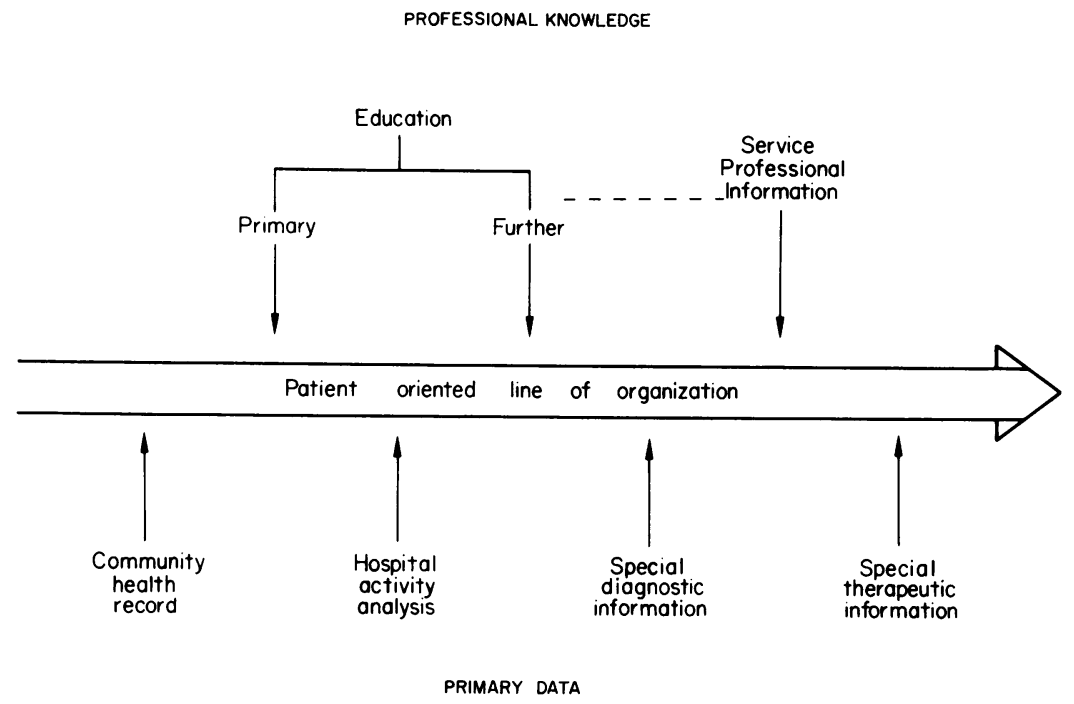

FIG. 1. Information requirements in hospitals: basic relationships.

eventually, the provision of linkages between people and information as well as between people and documents, together with the development of selective dissemination services. The Royal Commission on Medical Education (1968) has pointed out that the introduction of new and sophisticated techniques is likely to lead to important changes in medical practice. This implies constant awareness of current developments in medical and scientific knowledge and their applications, and this in turn demonstrates the inadequacies of present thinking about medical libraries and information services.

James Miller (1967) has described the American concept of a University Health Sciences Information Centre, and he maintains that information-processing is an essential and major part of the educational, clinical, research and service activities of the health sciences. Miller uses the term information-processing broadly to include the obtaining of information by individuals from some source in their environment, their association of it with other previously learned information, their storing of it in their memories, their making decisions on the basis of it, their creating new concepts and ideas, and their expressing such information in oral, written or other forms whereby it is transmitted to other individuals.

Medical information has one primary objective, the application of knowledge to the care of the patient, that is, it is directed towards the practice of medicine. There are, however, two distinct aspects of medical information which require separate consideration although they form an entity, with considerable interchange and overlapping. Fig. 1 sets out the basic relationships.
On the one side is the information which is regarded as part of the professional education of the doctor; its acquisition is a continuing process throughout the practitioner's life. Together with this is the information which may be required in connection with a particular patient, which may be purely reference knowledge where the doctor wishes to check a dosage, or a possible alternative diagnosis; as such the information then becomes part of the further education of the doctor. All this is part of the normal service of a medical information centre and the information may be stored in a variety of forms including the printed word, visual, audio, or micro-forms, or on punched card or tape, or within the computer itself.

The primary data, on the other hand, comprise the quantitative or numerical data which are part of the total field of hospital management, the basic data of hospital activity analysis, and also the full range of primary data originating from the patient himself. This may start with registration of birth, followed by the school health and immunological record and the adult health record maintained by the general practitioner. It is logical that this record should merge with hospital investigation and treatment data and that there should be adequate record linkage to provide sufficient information regarding the patient wherever and whenever it is required (Acheson, 1967). Much of this primary data will be required, in varying forms, often statistical, as the basic data for medical and nursing research and for this reason it would seem advisable that it should be in a form, preferably machine-readable, suitable for this purpose. The compatibility of 
information-handling equipment within the hospital situation should then receive due attention.

A wide range of computerized aids to medical and dental diagnosis has recently been developed (Miller, 1967). A medical information centre as proposed here would include on-line computer assistance in the following areas and would be available for research purposes: the reading, transmission and recording of electrocardiograms and electroencephalograms; X-ray interpretation; relating laboratory findings to diagnosis; recording medical histories, determining from the records significant factors relating to the incidence of disease, and evaluating differential diagnoses and prognoses. By using such techniques with the facility of rapid input and output it can be expected that current statistical methods and search strategies could be substantially altered. With such facilities available postgraduate clinical research (including general practice and nursing) would be encouraged and its results widely disseminated through a national co-ordinating network.

The primary requirements for information within the health sciences may then be regarded as being for education and for service. Because of the difficulty in separating these two requirements the information service must be regarded as a unity, but with differing emphasis. On the one hand there is the hospital information service controlling the service activities of the hospital and on the other, the professional information service consisting of a unit which would be a development of what is now known as the 'medical library'. This would be largely a communication centre with a varying amount of lccally held material-books, periodicals, report literature, audio-visual media and microfilms-but with access to materials or services elsewhere in the country. Communication methods would include traditional line methods, telefacsimile transmission, closed circuit television and direct computer network. The use of photocopying and microfilm would tend to replace conventional lending procedures.

The fundamental concept of such an information unit derives from the 'information explosion'. No single library or information centre can expect to acquire and process all the world's medical literature, or even a significant part of it without tremendous financial and staffing resources. The logical solution, which is now being studied, would be to set up a national information network for the health sciences. This would include not only biomedical and nursing literature but all aspects of hospital management and planning, and community and social medicine in its widest applications. This in turn will touch information services in the fields of science and technology as well as in sociology and the humanities. The ultimate objective would thus be a nationally organized information service covering the field of human knowledge with links to international information centres. Although at first sight this may seem an ambitious project, as indeed it is, yet it is not impossible of attainment for much exists at present. It is the basic co-ordinating network which requires to be formally established and the Office of Scientific and Technical Information could well be a prime mover for this purpose.

\section{Local information requirements}

Whatever the future may hold regarding the reorganization of the National Health Service-into regions or area health boards-there is little doubt that there will be a continuing trend towards comprehensive community health care. This implies a progressive development of co-ordination of medical information among practitioners in the community and in the hospitals. The concept of a district general hospital was proposed as the most practicable method of offering patients the full range of hospital facilities (Ministry of Health, Hospital Plan, 1962). It has also been regarded as the correct place to site the postgraduate centre as the focal point for the continuing education of all medical practitioners in the local area (HM (67)33). But it would seem that the logical further development of these centres will be towards them becoming the Health Sciences Information Centres of the future.

Because of the complexity of medical information, the need to educate and to keep informed all those comprising the health team, and the sophisticated and expensive techniques involved in information processing, it would seem essential that such facilities in these new information centres should be freely available to all those working within the health field both in the hospitals and in the community. This is not a new idea and has been developed along these lines in North America (Detwiller, 1963). An increasing range of professions and technologies are entering the hospital situation in support of modern medical practice, each with particular requirements for information. Many of these specialists need fast and efficient methods of information retrieval and often in subject areas not adequately covered by the MEDLARS services. Indeed, systems such as MEDLARS are becoming increasingly less useful since the volume of scientific literature is so great and since this retrieval system provides no index as to the quality or relevance of a particular article. Moreover, the time required to check each item of the long list of references may be inordinate for anything other than a very detailed review. It is probable that the multiple uses of a library and information service for specific problems encountered in medical practice can never be met by the MEDLARS-type system and that a more relevant 
solution would be for specialty groups to provide a weekly or monthly input to a library and information service for articles and other information of particular importance.

This suggests a new approach to the functions of medical libraries and the importance of regional medical information centres associated with a university medical school becomes clearly demonstrated. The need to control information in this way demands not only new techniques but also specialist staff for information-processing in the biomedical sciences. It is interesting to note the recent developments which have resulted in the emergence of information science as a professional discipline. It may well be that medical librarianship will develop new functions in the applications of information science to the field of medicine. But the problem is too complex and the methods of information control are too costly to allow a scattering of resources. Regional co-ordination within a national network of medical information services becomes necessary. Within such a framework postgraduate medical education could be greatly supported and the results of clinical research could be widely disseminated.

\section{Regional co-ordination of information services}

The Sheffield report of the Working Party on Medical Libraries (1965) has tended to become the basic document on regional library services. The Oxford Report (1968) has supplemented this but neither of these has directed sufficient attention to the future. Both reports advocate improvement of medical library facilities in their areas but suggest a situation which ought to have been available to the medical world many years ago. Today, industrial information services are using advanced techniques of information-processing while the hospital service is beginning to build postgraduate libraries of a very simple pattern. Although modern medicine is introducing sophisticated techniques and equipment with progressive automation in the hospitals, the latest advances in information retrieval have not been fully appreciated or applied to medical practice in this country. It is important, however, that medical libraries should be considered in the contemporary situation of information-processing in science and technology.

A discernible pattern of organization of biomedical information services which is firmly based upon a national and regional network of services is beginning to emerge. In the absence of a National Library of Medicine in this country the central collection of printed literature lies in the National Lending Library for Science and Technology. A similar collection of audio-visual materials has still to be organized but plans for this are being made.
The major bibliographical services in medicine will rely for some time yet on the American National Library of Medicine with additional support from the Excerpta Medica Foundation, but nursing and related health sciences are less well served. The availability of much of this kind of material in machine-readable form must be considered as well as the use of the computer for the 'publication' of highly specialized material.

At the regional level (this term is used loosely here with an open mind as to the future pattern of organization of the National Health Service) it would seem logical that a regional library and information service should be associated with a university medical library, preferably integrated, as at the new Southampton medical school, with a training centre for nursing. Such a regional centre would be the focus of a network of integrated library and information services to all health workers throughout the region. Area libraries may be required as front-line units acting as local centres for a number of hospital Groups within a geographical area. It will be readily appreciated that information is a universal commodity which tends to disregard existing administrative boundaries and restrictions (see Fig. 2).

Information-processing is a skilled task requiring sophisticated techniques and equipment. It is the nervous system of the health service and must be highly organized if efficient use is to be made of the resources of modern medicine. Possibly there will be in the hospitals of tomorrow two complementary information specialists; one, the hospital administrator/statistician who will direct the handling of the primary data of hospital activities, and the other, the medical information specialist, knowledgeable in the health sciences and skilled in the techniques of information retrieval. Together they would coordinate local educational efforts and service and research information needs both in the hospitals and in the community.

Overhage \& Harman (1965) have indicated that the 'library' of the future will be a large network of information transfer services co-ordinated by a central staff linked into a variety of sources and users. A network for the health sciences, as suggested in Fig. 2, would include academic centres, hospitals, research institutions, industry and government agencies and it is likely that such a library and information centre in the health field would make optimal use of three phases of technological development in the processing of information (Miller, 1967); phase 1, books and periodicals (basic printed word and visual materials); phase 2, microforms; and phase 3, electronic information-processing.

In phase 1 there would be basic organization of traditional library materials, all forms of print and 


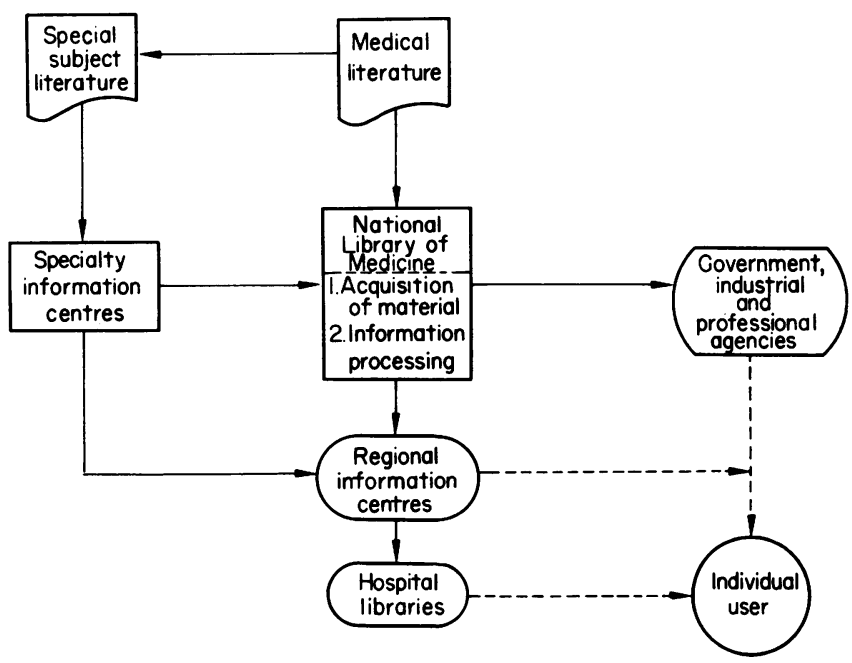

FIG. 2. A health sciences information network.

audio-visual items, interlibrary lending services and provision of copying facilities. The second phase would develop microform technology; advances in this field have shown its tremendous potential for greater efficiency in information handling and retrieval techniques. The FAIR project of the Medical Research Council's bio-medical engineering section has indicated how microfilm may be utilized to put on each doctor's or scientist's desk a complete library with its own indexing and retrieval device (Pickford, 1968). Electronic information processing in phase 3 will make available highly flexible methods of information manipulation including location of required items and rapid transfer facilities for on-the-spot use.

Already hospitals are being built to serve in the Twenty-first Century and the students of today will be senior consultants in the year AD 2000. It would seem logical to plan for this future by utilizing the latest techniques, particularly the computer and microfilm in the design of information systems in medicine. Too much time has been lost so far in developing these concepts, and only one Regional Hospital Board, Wessex, has started seriously to examine the problem and to formulate an answer. It is to be hoped that the current advances in information science and technology will soon be made available to all workers in the field of the health sciences.

\section{References}

Acheson, E.D. (1967) Medical Record Linkage: from the Oxford Linkage Study and the Unit of Clinical Epidemiology, Nuffield Department of Clinical Medicine, University of Oxford. Oxford University Press (for the Nuffield Provincial Hospital Trust).

Adams, S. (1968) Editorial. Bulletin of the Medical Library Association, 56 (2), 175.

Detwiller, L.F. (1963) New Health Sciences Centre for British Columbia. Canadian Hospital, pp. 1-4.

Lancet (1964) Editorial. i, 155.

Ministry of Health (1962) A Hospital Plan for England and Wales (Cmnd 1604). Her Majesty's Stationery Office, London.

MiLleR, J.G. (1967) Design for a University Health Sciences Information Centre. Journal of Medical Education, 42, 404.

Overhage, C.F.J. \& HaRman, R.J. (eds.) (1965) INTREX. Report of a Planning Conference on Information Transfer Experiments. M.I.T. Press, Massachusetts.

Pickford, A. (1968) FAIR Newsletter No. 9, November.

Pings, V.M. (1966) A crisis in research libraries. Library Journal, September, pp. 3876-82.

Sheffield Regional Hospital Board (1965) Working Party on Medical Libraries, final report.

UNIVERSITY OF OXFord (1968) Committee for Postgraduate Medical Studies. An integrated medical library service for the Oxford region: report of a joint working party. 